\title{
Effectiveness of a Lesson on Multimodal Writing in Science Education
}

\author{
Sakari Tolppanen \\ Unit of Chemistry Teacher Education, Department of Chemistry, University of Helsinki • \\ sakari.tolppanen@helsinki.fi \\ Toni Rantaniitty \\ Unit of Chemistry Teacher Education, Department of Chemistry, University of Helsinki \\ Mark McDermott \\ Wartburg College \\ Maija Aksela \\ Unit of Chemistry Teacher Education, Department of Chemistry, University of Helsinki \\ Brian Hand \\ College of Education, University of Iowa
}

\begin{abstract}
This study investigates how a multimodal writing lesson was received by 13 to 14 -year-olds in a science class. The research addresses the following research questions (i) how does a lesson on multimodal writing effect students' text production and use of alternative modes of representation in a science writing task, (ii) is there a gender difference in the use of multimodal writing, and (iii) how do different lesson structures affect students' ability to use multimodal writing. The principles of effective writing-to-learn lesson were implemented and the written products of 98 science students from three different schools were analyzed. Out of these students, 54 were given a lesson on multimodal writing and 44 were in a control group. Content analysis of the data showed that a single lesson on multimodal writing did not affect students' text production, but students in the test group used more alternative modes than students in the control group. However, this difference in quantity did not affect the quality of the end products. However, a significant difference in the use of multimodal writing was seen between genders, females outperforming males. Furthermore, some differences in lesson structures were noted, but evidence on their effect on learning is not evident. In conclusion, the findings suggest that a single lesson on multimodal writing is not enough for students to understand how to implement multimodal writing, but that good general writing skills benefit students in transferring from traditional writing to multimodal writing.
\end{abstract}

Keywords Multimodal writing, Alternative modes of representation, Writing-to-learn, Effective writing, Science education 


\section{Introduction}

\subsection{Writing-to-learn}

During the past decades, research has been conducted on how writing could be used as a tool to learn. Research shows that some of the positive outcomes of writing-to-learn tasks are increased reasoning skills, ability to describe scientific concepts and enhanced skills in formulating arguments (Wallace, Hand, \& Prain, 2004). Therefore, writing-to-learn activities are often used as a way of making sense of new ideas (Newell, 2006), as well as helping students deepen conceptual understanding (Holliday, Yore, \& Alvermann, 1994) and critical thinking skills (Kieft, Rijlaarsdam, \& van den Bergh, 2008).

Since the beginning of the writing-to-learn movement, researchers have attempted to find out what kind of writing tasks have the most positive learning effects (Yore, Bisanz, \& Hand, 2003), some of which are discussed in the next section. Though principles have been found, not all of them are directly transferable to science education, where writing assignments consist of, not only text, but also of other modes of representation, such as graphs, tables and diagrams (Lemke, 1998). Some research has already been done on how different characteristics of scientific writing can be implemented into teaching (Prain, 2006), but as this research will show, best practice of implementing multimodal writing into science education still needs to be examined.

\subsection{Effective writing tasks}

As early as in the 1980s it was noted that changing the audience the writing task is addressed to may affect the usefulness of the writing task (Hillocks, 1986). In a more recent study, positive effects were detected when directing a writing task to an "authentic" audience rather than to the teacher (Rijlaarsdam, Couzijn, Janssen, Braaksma, \& Kieft, 2006). Writing-to-learn activities, in which students are asked to write for different audiences require the students to translate the knowledge they possess, or find in books, into a language understandable by the audience (Gunel, Hand, \& McDermott, 2009). However, there has also been ongoing debate about whether informal writing or traditional writing (reports, experiments etc.) should be used to express and potentially build students' science understanding (Wallace et al., 2004). Both writing types have been advocated as being beneficial. Informal writing, or writing using everyday language, has been promoted as a way to talk to peers about early stage scientific understanding, but traditional scientific language is claimed to be more powerful in creating a more sustainable scientific understanding (Gee, 2001). Ideally, combining informal and traditional writing can help students verbalize scientific language while gaining a deeper understanding of science (Wallace et al., 2004).

A model of effective writing-to-learn activities has been developed by Prain and Hand (1996). In this model, the authors suggest that five key elements should be considered when creating a writing task designed to effectively promote learning. The first of these elements 
is topic, referring to the key concepts that the writing is dealing with. The second is type, specifying the type of writing task (narrative, letter, poem etc.). The third is purpose, meaning the role that the task has on concept development (review, clarify, apply etc.). The fourth is audience, referring to who the written task is directed to (peers, teacher, younger student, etc.) and the last is method of text production, referring to how the students will physically create the text (computer, pen, groups, etc.).

In a more recent study, Prain and Hand ( 2005) also suggest that in writing activities, students are engaged in translating data in three different ways. The first translation takes place when the student must translate the text for themselves so that they can understand the concept. The second translation is a process of changing the known concepts into a form that is directed at the audience: Understanding of the audience will influence how well this translation is carried out. The third translation happens when the learnt concepts have to be translated back into science, when completing other classroom assessments.

\subsection{Multimodal representations in writing}

Lemke (1998) has stated that science is not done and communicated with verbal language alone, but rather, combines verbal text with mathematical expressions, quantitative graphs, information tables, abstract diagrams, maps, drawings, photographs and requires a combination of visual tools seen nowhere else. In other words, science is communicated through multimodal representations. For students to understand science, it is therefore important that they are able to understand and use these multimodal representations. Furthermore, it is believed that teaching students to write using multimodal representations will help them build their conceptual understanding in science, as well as reap the other, previously mentioned, benefits of writing tasks (Bangert-Drowns, Hurley, \& Wilkinson, 2004; Prain, 2006).

When scientific knowledge is presented to students through different modes, students need to integrate the pieces of knowledge in order to form a more complete conceptual understanding of the topic (Airey \& Linder, 2006). According to Seufert (2003), students need to form referential connections between different modes, in order to progress through a more meaningful learning sequence. Also, according to diSessa (2004), obtaining a deeper understanding and being able to make interpretations of a topic is increased when different modes of representation are introduced. He also emphasizes that it is important that students not only learn to use and read different modes of interpretation, but learn about the limitations of different modes of representation as well as how they may be interpreted the wrong way. All of these authors write about the importance of exposing students to different modes of representation and point out that it is an important feature of the classroom environment.

The use of multimodal writing has also been tested in classroom settings. For instance, in a research conducted by Hand, Gunel, \& Ulu (2009), students were given different kinds of writing tasks, some of which required the use of multimodal writing and others that did 
not. Their post-test results show that students, who use mathematical equations to support their writing tasks in physics, understand the concepts better. Also, according to their research using other alternative modes, such as images, supports learning more than textonly tasks, but not as much when also mathematics is combines into the task. In another research by McDermott \& Hand (2012), a test group was given a single lesson on the use of multimodal writing. The students were then asked to complete a written assignment where they use multimodal writing, and assignments were compared to a control group who were given the same task. After completing the written assignments, students were tested on content knowledge and students from the test group seemed to outperform the control group.

However, despite these noted benefits, research has not consistently supported the benefits of writing-to-learn, or provided a clear indication of the most effective assignments for teaching multimodal writing (Galbraith \& Torrance, 1999; Holliday et al., 1994; Klein, 1999; Rivard, 1994; Yore et al., 2003). For instance, Nieswandt \& Bellomo (2009) have indicated that writing is not a completely suitable method to measure student learning in different contexts. Furthermore, though some research shows writing tasks increase student learning and metacognitive skill (Boscolo \& Mason, 2001; B. Hand, Wallace, \& Yang, 2004), others have shown mixed results (Ackerman, 1993), and in a meta-analysis, Bangert-Drowns et al., (2004) showed that positive effects are not common and effect sizes are small.

Therefore, best practices of writing-to-learn and the use of multiple modes of representation are not yet clear. However, as stated by Wallace et al. (2004), we believe that students learn to clarify their thoughts when seeking for the right form in which to present their ideas to an audience. Research done by Hand et al. (2009) has already given some indication of this and this research aims to expand on that. Therefore, this research does not look at whether students learn from multimodal writing or not, but rather, examines how students use multimodal writing as a way to present their ideas.

Furthermore, we aim to find out whether there is a difference in the use of modes between females and males. In a previous study done in Finland (Välijärvi et al., 2007), females have been shown to perform better at reading tasks than males, possibly also affecting their writing skills. In a study by Tarmo (1991), it was also argued that females in Finland do not understand science concepts as well as males, often finding them too abstract. However, this argument is not in accord with the PISA studies conducted in Finland, where gender differences were non-existent in science knowledge (Lavonen \& Laaksonen, 2009). Research does, however, show that females, more easily than males, perceive their understanding as lacking (Airey \& Linder, 2006). Assuming that gender differences do not exist in scientific knowledge and that females are better at writing than males, our results will shed light on whether multimodal writing skills are more related science knowledge or writing skills. 


\section{Aim}

The aim of this research is to answer the following questions:

1. How does a lesson on multimodal writing effect students' text production and use of alternative modes of representation in a science writing task?

2. Is there a gender difference in the use of multimodal writing?

3. How do different lesson structures affect students' ability to use multimodal writing?

Based on these results, we will discuss whether a single lesson on multimodal writing helps students assess their own writing and how the use of multimodal writing tasks can be implemented into the classroom.

\section{Method}

\subsection{Participants}

This study was carried out in three randomly selected schools in the capital region of Helsinki, Finland. A total of 98 grade 8 (13 to 14-year-old) students participated in this study. Out of them, 54 students were in the test group and 44 in the control group and 53 were male and 45 were female.

School A was a regular Finnish comprehensive school, consisting of grades 7-9. From school A, 41 students took part in the study, out of which 27 were part of the test group. The teacher giving the lesson in school A had 6 years of teaching experience and she gave the lesson on multimodal writing to two student groups ( $\mathrm{N}=13$ and $\mathrm{N}=14)$. The control-group was given a regular lesson by the teacher and the class consisted of 14 students.

School B has students from grade 7 to grade 12, a comprehensive school and an upper secondary school being in the same building. The upper secondary school (grade 10-12) offers a special science program. The students in this study were in grade 8 and therefore were not a part of the science program. However, the teacher teaching the class also teaches courses in the science program, possibly affecting their teaching methods and level of motivation. From school B, 43 students took part in this study, 27 being in the test group and 17 being in the control group. The teacher in school B had 5 years of teaching experience and she gave the lesson on multimodal writing to two student groups $(\mathrm{N}=12$ and $\mathrm{N}=15$ ).

School C was also a comprehensive school. In school C, the teacher was unable to give the lesson on multimodal writing due to changes in school schedules, so data was collected only from the control group of 14 students. The teacher in school $\mathrm{C}$ had 12 years of teaching experience. 


\subsection{Multimodal writing lesson}

In a previous research (McDermott \& Hand, 2012), a single lesson on multimodal writing has been shown to increase students' content knowledge, therefore, a single lesson approach was used also in this research.

Two weeks before the scheduled lesson, researchers met up with each teacher and told them that the aim of the research was to examine the effects of a single lesson on multimodal writing on students' ability to use alternative modes of representation. Teachers were then instructed on how to give a lesson on multimodal writing by discussing the following step-by-step instructions with them:

1. Give students a text description of a challenging topic, which is closely aligned to a current concept being dealt with in the class. The text should not have any alternative modes of representation other than text.

2. Ask students to analyze the text and think of ways how effective the text is in communicating the scientific information.

3. Ask students to look at different science sources and analyze how they use alternative modes of representation to support written communication (tables, graphs, image etc.).

4. Based on their observations, ask students to generate a list of the alternative modes used in common science sources (text book, magazine etc.) and how they are linked together.

5. Based on their list, guide students in generating an assessment matrix, which they can then use to evaluate the use of alternative modes of representation.

6. Practice using the matrix to analyze a scientific source with students.

7. Give students homework where they need to practice using the matrix created to analyze a scientific writing.

8. Refer to multimodal writing in the following lessons.

9. After two weeks, give the students an assignment, where they need to write to an authority about an issue dealt with in class. Give instructions to use both written text and alternative modes of representation when explaining the issue.

During the multi-modal lesson, teachers were asked to keep track of how much time they used for each section of the lesson and mark these down on a table provided for them.

Each of the three schools was teaching a different topic in science, therefore, they used a different initial text (1), analyzed different sources (3) and were given homework (7) relating to the theme they were studying. As homework, teachers asked the students to write a text where they use alternative modes of representation. Students were instructed to do the assignment using the guidelines of the matrix created. In school A, the assignment was done on refining metals and in school B the assignment was on alcohols.

While the test group had the lesson on multimodal writing, the control group was taught a traditional lesson on the same science theme that the multimodal writing lesson dealt 
with. The control group was given the same homework as the test group, but the use of alternative modes was not emphasized.

\subsection{Writing Assignment}

Two weeks after the lesson on multimodal writing, the students were given an assignment in which they were told that they are the editor of a science magazine and need to provide an answer to one of the questions that was asked by a reader. The assignment was related to the topic they had been studying in the previous class. Students in school A wrote about fats and carbohydrates, students from school B wrote about electricity and students from school $\mathrm{C}$ wrote about the expansion of metals.

The assignments were created so that they considered the model for an effective writingto-learn activity (Prain \& Hand, 1996), namely students were asked to write to someone who did not yet understand a concept that they understood themselves. For example, the assignment given to school $\mathrm{C}$ was as follows:

You are the editor of a science magazine and you are given the task to answer a question asked by the reader.

Question: Years ago when I was traveling, I noticed that on a hot summer day the railway tracks were so bent that the railway traffic needed to be stopped. However, it did not seem like the tracks were bent by human force. Is there a scientific explanation to this?

In the task, students were asked to use multimodal writing to bring across their ideas. The students had one week to complete the assignment as homework.

The control group and the test group were given the same assignment and the same instructions to complete the task, except that the students in the test group were asked to reflect on the earlier lesson on multimodal writing.

\section{Data analysis}

In this research, the text production and the use of alternative modes was analyzed utilizing a rubric that was similar to one used in previous research (McDermott \& Hand, 2012). The rubric has been developed by consulting international researchers who have done multimodal writing research in the past as well as referring to previous research on the subject (McDermott \& Hand, 2012). For this research, small adjustments were made to the rubric, namely characteristics of "original" and "model is self-explanatory" were omitted, as they were seen as hard to interpret or irrelevant for this research.

Using this rubric, the data collected from the students was evaluated on three different characteristics: text production, general mode-analysis, and individual mode-analysis. The text production examined the use of text in explaining ideas. The general and individual mode analysis examined how other alternative modes of representation, such as images, tables and graphs, were used to explain an idea. Each of these three sections contained sub-categories that were given a score between $0-2$, as explained below. The score was given using the guidelines explained below and discussion among researchers 
how these guidelines are interpreted. After giving the scores in text production, general mode-analysis and individual mode-analysis, the data was analyzed using Mann-Whitney U-test as the data was small and not normally distributed.

\subsection{Part I: Text production}

The Text production was comprised of analyzing both Assignment Expectations and Audience Consideration. In Assignment Expectations, the writing process was analysed with the following characteristics:

- Grammar: Students wrote the text according to grammar rules and avoided misspelling.

- Coverage of Required Topics: Students presented the main contents of the topic required by the assignment.

- Accuracy of Science Concepts: Students accurately described the science content discussed in the written product.

- Completeness of Meaning: Students thoroughly covered all aspects of required topics.

- Logical Order of Text: The chapters/paragraphs were in a logical order and the writing was well paced.

In Audience Considerations, the suitability for the audience was analysed based on the following characteristics:

- Appropriate Language / Vocabulary: Students used language appropriate for the audience.

- Identification of Key Terms (Underlined, Highlighted, Italics): Students emphasized the key terms associated with the topic by underlining, highlighting and the appropriate use of italics.

- Headings: Students used logical headings, and started writing with a form that addresses the reader (e.g. Dear, Sir / Madam...)

For each of the five characteristics in Assignment Expectations, and for the appropriate language/vocabulary characteristic in Audience Consideration, a score of zero, one or two points were given, depending on how expectations were met. Zero points was given if no evidence of the characteristic was presented, one point was given when there was some evidence that the characteristic was present and two points when the characteristic was applied throughout the task. The characteristics of Identified Key Terms and Headings in Audience Consideration were evaluated with a two-point scale, where o points was given if a characteristic was not employed at all, and 1 point was given if the characteristic was utilized. Therefore, in text production, a student could attain a maximum score of 14 points. 


\subsection{Part II: General Alternative Mode Analysis}

The General Alternative Mode Analysis focused on the different modes students utilized and how appropriate they were for the task. In this part of the analysis, a general analysis of modes was undertaken by exploring the following characteristics:

- Modes appropriate for audience: The modes were classified as appropriate when students took into account the audience and their preliminary knowledge of the topic.

- Key terms included in modes: The key terms appeared in modes, which helped the audience understand what specific information the modes presented.

- Accurate / Correct representations: The content included in the modes was scientifically accurate/correct.

- Modes Linked to Main Concepts: The context of the modes was related to the topic or linked to main concepts.

- Logical Distribution of Modes: The student placed the modes in a logical order in respect to the written text.

As in the previous section, the characteristics were given a score of zero, one or two depending on how well they were implemented. The maximum amount of points from General Alternative Modes Analysis was therefore 10 points.

\subsection{Part III: Individual Alternative Mode Analysis}

In the third part of the analysis, each mode was studied individually. The evaluation of the individual modes focused on A) Embeddedness Strategies and B) Characteristics. Embeddedness Strategies evaluate how students linked their modes to text using the following criteria:

- Caption: Students used captions to explain the content of the modes.

- Next to Appropriate Text: Students' modes had the same content or dealt with the same content as the text close to them.

- Referred to in Text: Students referenced their modes in text, for example "As the figure above showed..."

- Explained in Text: Students explained the modes or the content of the modes in text.

Characteristics was analysed by including the following criteria for the evaluation:

- Scientifically accurate: The individual mode was scientifically accurate.

- Necessary for Explanation: Modes and captions were understandable together, helping the audience understand what topics were presented.

- Conceptual Connection to Text: The concepts presented in the individual modes were relevant to the topic of the written text.

In Embeddedness Strategies, a score of o (not employed) or 1 (utilized) was given based on the quality of the mode. In Characteristics, a score of o (no attempt), 1 (limited attempt) or 2 (entire/complete) was given, based on the quality of the mode. 
The maximum amount of points attained from Individual Alternative Mode Analysis was therefore 10 points.

\section{Results}

This section will firstly look at what kind of effects does a single lesson on multimodal writing have on text production and the use of alternative modes. It will then look at the effect of gender on the use of multimodal writing, and finally, examine the effects of the differences in lesson plans.

\subsection{The effects of a lesson on multimodal writing on text production and use of alternative modes}

When the test group and the control group were compared with each other, some differences were found in the way students used text and alternative modes of representation.

When analyzing the use of text production, it was noted that out of the test group $(n=54), 8$ students did not use text in their assignment. Without written text, the message of the student's letter was unclear, and therefore these results were omitted from the analysis. When analyzing the remaining texts $(\mathrm{n}=90)$, the test group $(\mathrm{M}=0.46, \mathrm{SD}=0.504)$ outperformed $(\mathrm{Z}=-2.521, \mathrm{p}<0.05)$ the control group $(\mathrm{M}=0.20, \mathrm{SD}=0.408)$ in the use of headings. As seen from the mean value, this was mainly due to the fact that the control group did not use headings at all. Significant differences were not found in the other groups.

When observing the use of alternative modes, analysis showed that 20\% ( $n=11)$ of the test group and $43 \%(n=19)$ of the control group did not use alternative modes of representation to support their text. A total of 68 students used alternative modes to support their text. The students used a total of 104 alternative modes, 67 by the test group and 37 by the control group. Among the students who did use alternative modes or representation, students from the test group used an average of 1.56 modes and the control group used an average of 1.48 modes in their assignment. When those students not using alternative modes $(\mathrm{n}=30)$ were omitted, the control group $(\mathrm{M}=1.32, \mathrm{SD}=0.476)$ outperformed $(\mathrm{Z}=-2.810, \mathrm{p}<0.01)$ the test group $(\mathrm{M}=0.86, \mathrm{SD}=0.675)$ in logical distribution of general alternative modes. In the individual alternative modes, the control group ( $\mathrm{M}=0.19, \mathrm{SD}=0.397)$ outperformed $(\mathrm{Z}=-2.352, \mathrm{p}<0.05)$ the test group $(\mathrm{M}=0.05$, $\mathrm{SD}=0.210$ ) in referring to their modes in text.

\subsection{The effect of gender on the use of multimodal writing}

Differences between the use of text production and alternative modes of representations were seen in females and males.

In the text production, significant differences between genders were seen in most of the characteristics assessed. When both the test group and control group were analyzed together $(\mathrm{N}=68)$, females outperformed males in Grammar $(\mathrm{Z}=-2.110, \mathrm{p}<0.05)$, accuracy 
of science concepts $(\mathrm{Z}=-2.097, \mathrm{p}<0.05)$ Completeness of meaning $(\mathrm{Z}=-2.409, \mathrm{p}<0.05)$ and appropriate language/vocabulary $(\mathrm{Z}=-3.785, \mathrm{p}<0.001)$. As a result, when all of the characteristics of text production were combined to one overall total value, females outperformed males significantly $(Z=-3.340, p<0.01)$. See table 1 for mean and SD values.

Table 1. Gender differences in text production

\begin{tabular}{lllllll}
\hline Gender & & Grammar & $\begin{array}{l}\text { Accuracy of } \\
\text { Scientific } \\
\text { Concepts }\end{array}$ & $\begin{array}{l}\text { Completeness of } \\
\text { Meaning }\end{array}$ & $\begin{array}{l}\text { Appropriate } \\
\text { Language }\end{array}$ & Total \\
\hline \multirow{4}{*}{ Male } & Mean & 1,44 & 1,07 & 1,53 & 1,24 & 8,18 \\
& $\mathrm{~N}$ & 45 & 45 & 45 & 45 & 45 \\
& $\mathrm{SD}$ &, 503 &, 654 &, 661 &, 609 & 2,790 \\
& Mean & 1,67 & 1,36 & 1,82 & 1,71 & 9,91 \\
Female & $\mathrm{N}$ & 45 & 45 & 45 & 45 & 45 \\
& $\mathrm{SD}$ &, 477 &, 645 &, 442 &, 506 & 2,448 \\
& Mean & 1,56 & 1,21 & 1,68 & 1,48 & 9,04 \\
\multirow{5}{*}{ Total } & $\mathrm{N}$ & 90 & 90 & 90 & 90 & 90 \\
& $\mathrm{SD}$ &, 500 &, 662 &, 577 &, 604 & 2,752 \\
\hline
\end{tabular}

When genders were compared in the test-group $(\mathrm{N}=46)$ only, females outperformed males in coverage of required topic $(\mathrm{Z}=-2.772, \mathrm{p}<0.01)$, Completeness of meaning $(\mathrm{Z}=-$ 2.528, $\mathrm{p}<0.05)$ and Appropriate language/vocabulary $(\mathrm{Z}=-4,611, \mathrm{p}<0.001)$. As a result, when all of the characteristics of text production were combined to one overall total value, females outperformed males significantly $(Z=-3.674, p<0.001)$ (see table 2$)$. When gender differences were observed from the control group $(\mathrm{N}=44)$ significant differences between males and females were not noted.

Table 2. Gender differences in text production within test group

\begin{tabular}{llllll}
\hline Gender & & $\begin{array}{l}\text { Covarage of } \\
\text { Required Topics }\end{array}$ & $\begin{array}{l}\text { Completeness of } \\
\text { Meaning }\end{array}$ & $\begin{array}{l}\text { Appropriate } \\
\text { Language }\end{array}$ & Total \\
\hline \multirow{4}{*}{ Male } & Mean & 1,00 & 1,41 & 1,15 & 7,81 \\
& $\mathrm{~N}$ & 27 & 27 & 27 & 27 \\
& $\mathrm{SD}$ &, 620 &, 747 &, 662 & 3,039 \\
& Mean & 1,53 & 1,89 & 2,00 & 10,84 \\
Female & $\mathrm{N}$ & 19 & 19 & 19 & 19 \\
& $\mathrm{SD}$ &, 513 &, 315 &, 000 & 1,463 \\
& Mean & 1,22 & 1,61 & 1,50 & 9,07 \\
Total & $\mathrm{N}$ & 46 & 46 & 46 & 46 \\
& $\mathrm{SD}$ &, 629 &, 649 &, 658 & 2,909 \\
\hline
\end{tabular}


In the use of alternative modes of representation, gender differences were also noted. When both the test-group and control-group were analyzed simultaneously in the use of General Alternative Modes, females outperformed males in modes linked to main concepts $(\mathrm{Z}=-2.537, \mathrm{p}<0.05)$ as well as logical distribution of modes $(\mathrm{Z}=-2.687, \mathrm{p}<0.01)$. The same differences were found when only analyzing gender differences in the test group $(Z=-2.200$, $\mathrm{p}<0.05$ and $\mathrm{Z}=-2.003, \mathrm{p}<0.05$ respectively) (See table 3). However, analysis of only the control group was not possible, as the group was too small after zero values were omitted.

Table 3. General alternative modes of test group

\begin{tabular}{|c|c|c|c|c|}
\hline \multicolumn{2}{|l|}{ Gender } & \multirow{2}{*}{$\begin{array}{l}\text { Modes Linked to } \\
\text { Main Concepts } \\
1,74\end{array}$} & \multirow{2}{*}{$\begin{array}{l}\text { Logical Distribution of } \\
\text { Modes } \\
\text {,70 }\end{array}$} & \multirow{2}{*}{$\begin{array}{l}\text { Total } \\
6,78\end{array}$} \\
\hline & Mean & & & \\
\hline \multirow[t]{3}{*}{ Male } & $\mathrm{N}$ & 27 & 27 & 27 \\
\hline & $\mathrm{SD}$ & ,447 & ,669 & 1,968 \\
\hline & Mean & 2,00 & 1,13 & 8,25 \\
\hline \multirow[t]{3}{*}{ Female } & $\mathrm{N}$ & 16 & 16 & 16 \\
\hline & SD & , 000 & 619 & 1,571 \\
\hline & Mean & 1,84 & ,86 & 7,33 \\
\hline \multirow[t]{2}{*}{ Total } & $\mathrm{N}$ & 43 & 43 & 43 \\
\hline & SD & ,374 & ,675 & 1,948 \\
\hline
\end{tabular}

When comparing the Individual Alternative Modes, females outperformed males in explaining their modes in text $(\mathrm{Z}=-3.271, \mathrm{p}<0.01)$, scientific accuracy $(\mathrm{Z}=-2.154, \mathrm{p}<0.05)$ and in making conceptual connections to text $(\mathrm{Z}=-2.527, \mathrm{p}<0.05)$. Furthermore, the Individual Mode Analysis showed that when all the characteristics within the group are analyzed simultaneously, females outperformed $(Z=-2.578, p=0.01)$ males significantly. When only the test-group was examined, females outperformed males in Location ( $\mathrm{Z}=-$ 2.352, $\mathrm{p}<0.05)$ and in explanation $(\mathrm{Z}=-3.671, \mathrm{p}<0.001)$. Furthermore, the Individual Mode Analysis showed that when all the characteristics within the group are analyzed simultaneously, females outperformed $(Z=-2.170, p<0.05)$ males significantly. See table 4 for mean and SD values.

Out of the males ( $n=53), 15$ (28\%) did not use multiple modes of representation and 8 did not use text in their assignments. Out of the females $(n=45), 15(33 \%)$ did not use alternative modes of representation, but all of them used text. From those who used alternative modes, the females used an average of 1.77 , and males an average of 1.34 modes.

\subsection{The effect of lesson plan on the use of multimodal writing}

As each teacher has their own style of teaching, some differences between the lessons taught on multimodal writing were observed. First off, the teacher from school A used 57 
Table 4. Gender differences in individual alternative modes within test group

\begin{tabular}{lllll}
\hline Gender & & $\begin{array}{l}\text { Next to } \\
\text { Appropriate Text }\end{array}$ & Explained in Text & Total \\
\hline \multirow{4}{*}{ Male } & Mean &, 43 &, 46 & 5,78 \\
& $\mathrm{~N}$ & 37 & 37 & 37 \\
& $\mathrm{SD}$ &, 502 &, 505 & 2,002 \\
& Mean &, 72 &, 90 & 6,83 \\
Female & $\mathrm{N}$ & 29 & 29 & 29 \\
& $\mathrm{SD}$ &, 455 &, 310 & 1,416 \\
& Mean &, 56 &, 65 & 6,24 \\
Total & $\mathrm{N}$ & 66 & 66 & 66 \\
& $\mathrm{SD}$ &, 500 &, 480 & 1,832 \\
\hline
\end{tabular}

minutes to go through the lesson on multimodal writing but the teacher from school B only used 40 minutes as they decided to leave out steps 6 and 7 seeing them as non-beneficial.

Secondly, in school B, slightly more time (10 $\mathrm{min}$ vs. $8 \mathrm{~min}$ ) was given to analyze the text-only description, given to the students at the beginning of the class. Also, in school B, $50 \%$ more time (15 min vs. $10 \mathrm{~min}$ ) was spent looking at how different modes of representation are used in different sources.

When analyzing the sources, school B only analyzed their own text-book, whereas school A looked at their textbook and Wikipedia. Since schools have the possibility to choose their own textbooks, the two schools were using different textbooks. A textbook analysis showed that the textbook of school A uses different modes of presentation more frequently than the book used at school B. However, in the book used by school A, modes were missing captions and explanations, and some images seemed irrelevant. In the book used by school B, different modes of presentation were strategically placed in the text, explanations of modes was always present and images were used in a way that supports the content of the text.

In both of the schools, the students made a list of the different modes that they found and formed a matrix out of them. However, only in school A the students practiced using this matrix on a new scientific source to evaluate the use of modes in that text.

After the lesson, homework was assigned in both schools. In school A, the homework was to practice the use of the matrix on an own written assignment, whereas in school B, students were instructed to pay close attention to how they use different modes of presentation in a written task.

Also in the follow-up lessons, school B used a more open approach, as students were asked to pay attention to the use of different modes of presentation, whereas in school A, the teacher talked about facts on how multiple modes of presentation were used in different sources.

Due to large amount of students who did not use either written text or alternative modes, comparing the test group and control group in text production and general 
alternative modes was impossible due to small sample size. However, analysis on the individual alternative modes was possible. In the test group, school B outperformed school A in Location $(Z=-3.344, p=0.001)$, explanation $(Z=-3,154, p<0.01)$ accuracy $(Z=-4.428$, $\mathrm{p}<0.01)$, connection to text $(\mathrm{Z}=-2.499, \mathrm{p}<0.05)$ and total $(\mathrm{Z}=-3.861, \mathrm{p}<0.001)$. See table 5 for mean and SD values.

Table 5. School differences in the use of alternative modes within test group

\begin{tabular}{lllllll}
\hline School & & $\begin{array}{l}\text { Next to } \\
\text { Appropriate } \\
\text { Text }\end{array}$ & $\begin{array}{l}\text { Explained } \\
\text { in Text }\end{array}$ & $\begin{array}{l}\text { Scientifically } \\
\text { Accurate }\end{array}$ & $\begin{array}{l}\text { Conceptual } \\
\text { Connections to } \\
\text { Text }\end{array}$ & Total \\
\hline \multirow{4}{*}{ A } & Mean &, 38 &, 49 & 1,11 & 1,68 & 5,49 \\
& N & 37 & 37 & 37 & 37 & 37 \\
& SD &, 492 &, 507 &, 567 &, 475 & 1,820 \\
& Mean &, 79 &, 86 & 1,76 & 1,93 & 7,21 \\
B & N & 29 & 29 & 29 & 29 & 29 \\
& SD &, 412 &, 351 &, 435 &, 258 & 1,346 \\
& Mean &, 56 &, 65 & 1,39 & 1,79 & 6,24 \\
Total & N & 66 & 66 & 66 & 66 & 66 \\
& SD &, 500 &, 480 &, 605 &, 412 & 1,832 \\
\hline
\end{tabular}

The opposite differences were seen in the control group as school 1 outperformed school 3 in captions $(\mathrm{Z}=-2.866, \mathrm{p}<\mathrm{0.01})$, necessary for explanation $(\mathrm{Z}=-2.340, \mathrm{p}<0.05)$, conceptual connection to text $(\mathrm{Z}=-2.911, \mathrm{p}<0.01)$. Also, when all of the sections in individual alternative modes were analyzed together, a significant difference was noted $(\mathrm{Z}=-\mathbf{2 . 0 3 9}, \mathrm{p}<0.05)$. However, in the control group the sample size was so small $(\mathrm{N}=24)$ that the data cannot be considered representative.

Table 6. School differences in the use alternative modes within control group

\begin{tabular}{llllll}
\hline School & & Caption & $\begin{array}{l}\text { Necessary for } \\
\text { Explanation }\end{array}$ & $\begin{array}{l}\text { Conceptual } \\
\text { Connections to Text }\end{array}$ & Total \\
\hline \multirow{4}{*}{ A } & Mean &, 57 & 1,43 & 2,00 & 7,00 \\
& N & 14 & 14 & 14 & 14 \\
& SD &, 514 &, 514 &, ooo & 1,359 \\
& Mean &, oo & 1,00 & 1,50 & 5,80 \\
B & N & 10 & 10 & 10 & 10 \\
& SD &, OOO &, ,oo &, 527 & 1,033 \\
& Mean &, 33 & 1,25 & 1,79 & 6,50 \\
Total & N & 24 & 24 & 24 & 24 \\
& SD &, 482 &, 442 &, 415 & 1,351 \\
\hline
\end{tabular}




\section{Discussion}

\subsection{Difference between test group and control group}

This research gives insight on the effectiveness of a single multimodal writing lesson. When comparing the test group and control group, it is seen that a single lesson on multimodal writing did not have an impact on students' text production. This is a logical result, when realizing that all of the characteristics assessed require a clear understanding of writing structure: something not obtained over one lesson. However, the one thing that showed a difference between the test and control group was the use of headings. It seems that the use of headings is something that is easily implemented into writing once the students are made aware of them. Therefore, it seems that the lesson gave students some idea on how they could improve their text, but more in depth lessons would be required to truly address the importance of text in multimodal writing.

The negative consequence of the multimodal writing lesson was that 8 students from the test group did not complete the task correctly, as they only used an alternative mode, rather than multimodal writing. The reason for this could be that students tend to do what they expect will be assessed (Snyder, 1973). This problem, however, could be overcome with further instruction on the importance of text, to which alternative modes need to be linked to. Also, asking students to analyse their own or each other's works could prevent this problem from reoccurring.

Though the text production was not greatly improved by the lesson, the difference on the use of alternative modes of representation was clear between the two groups. Taking part in the lesson greatly increased the use of alternative modes, as $80 \%$ of the test group but only $57 \%$ of the control group used them to support their writing.

However, the increased use in alternative modes did not increase their quality. In fact, the control group performed better in both the distribution of modes, as well as referring to modes in their text. One possible explanation for this could be that the students in the test group had a greater urge to use alternative modes of representation, but they had not yet understood how to use them correctly. The students from the test group, who were new to using alternative modes, could have, therefore, decreased the average scores of the test group. In comparison, based on the low percentage of use of alternative modes in the control group, we assume that only those who were previously familiar, or confident in using alternative modes, did so.

These findings seems to indicate that the lesson on multimodal writing did not help the test group understand the role of multimodal writing: At least not to the extent that they can help a reader further understand a concept, as Seufert (2003) says should be the aim. Furthermore, if students discovered the role of multimodal writing, it could be used as a way of making sense of new ideas (Newell, 2006). However, this was not seen in the results, as students scored relatively low on accuracy in both text and their alternative modes. Therefore, further research on how to emphasize the importance of multimodal writing 
needs to be conducted. Implementing multimodal writing into several lessons could help students understand the role of the alternative modes, but also, lesson plans should be modified to examine which teaching techniques work best.

Though a difference in the use of alternative modes of representation was seen between the two groups, caution must be taken when making conclusions from the findings, as the data was relatively small and a large amount of students did not use alternative modes $(\mathrm{n}=30,31 \%)$ at all. On the other hand, these students mainly consisted of the control group, showing that after a single lesson, using alternative modes was more common. However, from this data is it impossible to conclude whether the test group used alternative modes of representation because they found it to support understanding, or because they thought that the use of alternative modes is expected of them by their teacher. Furthermore, it is possible that greater difference between the two groups was not seen because the same teacher was teaching both the test and control group. Therefore, it is possible that the teacher implemented discussion on multimodal writing into the lessons of the control group even without realizing it. However, it would seem unlikely that the teacher would be able to implement much explicit or implicit teaching on multimodal writing into the lessons of the control group without realizing it. Therefore, we assume that the minor differences between the test and control group are primarily due to the lack of instruction received by the test group.

\subsection{The effect of gender on the use of multimodal writing}

Based on the fact that gender differences did occur in the test group, but not the control group, this research seems to indicate that females understand the importance of written text in multimodal writing better than males. Earlier research (Välijärvi et al., 2007) has already shown that in Finland there is a large gap in reading skills between males and females, and this research implies that this gap may also transfer into writing. However, this finding is not unexpected as (Fitzgerald \& Shanahan, 2000) have shown that a correlation between reading and writing skills often exists. What is more interesting is why this happens to the test group and not the control group.

We suggest that a single lesson on multimodal writing can improve the awareness of the importance of writing. Through this awareness, females put more effort into writing. However, this does not seem to impact males in the same way, which would explain why more significant differences were not noted when comparing the test group and control group.

At first, it may seem that this conclusion is not in accord with the PISA studies conducted in Finland, where gender differences were shown to be close to non-existent in science knowledge (Lavonen \& Laaksonen, 2009). However, the areas females scored higher in, do not indicate higher science knowledge, but rather, higher ability to use writing more effectively. 
Furthermore, this research implies that higher writing capability also reflects on the ability to use alternative modes of representation more accurately. This relationship is especially seen in the level of Individual Alternative Modes, where females outperformed males in several assessed categories. Besides the possibility that writing capability reflects the ability to use alternative modes, it is also possible that females realize that the reader's understanding on the topic may be lacking. According to a recent study (Airey \& Linder, 2006), females perceive their understanding to be lacking more easily than males. We believe that this belief could transfer into how the females see the audience. This idea is supported by the fact that females tend to use more modes in their writing than males (mean of 1,77 and 1,34 respectively).

Despite the fact that females were better at using alternative modes of representation, they were also more likely not to use modes in supporting their text. Though the difference between males and females using modes was not great ( $72 \%$ and $67 \%$ respectively), it is still evident that both genders need further education on the importance of using alternative modes of representation to support their scientific writing.

Finally, it is important to remember that the gender difference could be caused by the interest in the topics given. Some students may find a specific writing topic uninteresting or difficult, causing them to be less motivated about the given task, as seen in previous research (Gee, 2004; Räsänen, 1991; Tarmo, 1991). Interest could also play a role in reading and writing, as seen in a research done by The Finnish National Board of Education (Lappalainen, 2011). In this study, especially the topic on fats and carbohydrates could be assumed to interest females more than males. However, as all of the schools had different topics, it is not likely that all of the topics would be such where females favored the topic more than males.

\subsection{The effect of the lesson plan on the use of multimodal writing}

Qualitative differences were noted in the lesson plans mainly in the amount of time used in different sections of the lesson. However, because of the small size of the test groups, comparing the lessons was only possible by assessing the individual alternative modes. These results show a clear difference in the schools, school B outperforming school A in several of the categories. However, due to the small size of the control groups, we were not able to examine whether similar significances are present there, though our tests do seem to point to an opposite situation, where school A outperformed school B.

It seems most likely that the difference in schools is caused by something this research did not touch on. Firstly, school A used more time on the lesson on multimodal writing, and students had a chance to practice using their matrix, so the lesson seemed to be more useful. Secondly, school B is connected to a science-oriented upper secondary school. The teachers therefore teach in both the junior high and the senior high, so their expectations and teaching methods may differ from the teachers of other schools. An example of this was seen in how the teachers in school B decided to omit the practice of the matrix and gave the 
students a more open-ended homework assignment. Their vast experience with different kinds of students has the potential to increase their efficacy, a trait that is seen as one of the most important teacher traits to increase student motivation and learning (Ashton, 1984).

Finally, the third explanation could be the text books used in the schools. School B used a text book that, though it used fewer alternative modes of representation than the book used by school A, used them more correctly. For instance, in the book used by school B, the alternative modes of representation were used more effectively to explain the context of the text, whereas in the book used by school A, some of the alternative modes tended to be irrelevant. As the text book is one of the primary sources from where students learn, they are most likely influenced by the way things are represented in the book. This idea is supported by diSessa (2004), who claims that when different modes of representation are introduced, students get a deeper understanding of a science topic. And as a student's reading comprehension increases, they are also more able to present their ideas in writing (Shanahan \& Lomax, 1986; Shanahan \& Lomax, 1988).

Since school differences did occur, it is hard to say how much these results effect the comparison between the test group and the control group. Theoretically it is possible that, for instance, the control group from school B did better in all aspects of multimodal writing than the test group in school A, but due to the small school and class sizes in Finland, collecting enough data to compare these two is difficult.

\section{Conclusions}

This research found that a single lesson on multimodal writing increases the amount of multimodal representations used by students taking part in the lesson. However, it also suggests that teaching a single lesson on multimodal writing is not sufficient to increase the quality of the alternative modes used. From these findings, we conclude that a single lesson on multimodal writing will help students understand the importance of multimodal writing, but is not enough for students to gain understanding on how alternative modes should be used correctly. Therefore, further research is needed on how to best implement multimodal writing lessons into school.

This research also implies that a link between students writing skills and the use of alternative modes exists. Further research on this link is required, but if this link is realized, it would imply that writing tasks given in class would also increase level of multimodal writing. Though the writing tasks would not initially consist of multimodal writing, sufficient writing skills will help the transfer into multimodal writing, when it is discussed in class.

\section{Acknowledgements}

We would like to thank the teachers who gave their valuable time in order to make this research possible. 


\section{References}

Ackerman, J. M. (1993). The promise of writing to learn. Written Communication, 1O(3), 334-370.

Airey, J., \& Linder, C. (2006). Languages, modality and disciplinary knowledge. Unpublished manuscript from http://www.slidefinder.net $/ \mathrm{m} / \mathrm{multimod} / \mathrm{multimod} / 15642224$

Ashton, P. (1984). Teacher efficacy: A motivational paradigm for effective teacher education. Journal of Teacher Education, 35(5), 28-32. doi:10.1177/002248718403500507

Bangert-Drowns, R., Hurley, M. M., \& Wilkinson, B. (2004). The effects of school-based writing-tolearn interventions on academic achievement: A meta-analysis. Review of Educational Research, 74(1), 29-58. Retrieved from http://rer.sagepub.com/content/74/1/29.abstract

Boscolo, P., \& Mason, L. (2001). Writing to learn, writing to transfer. In L. M. Tynjala, \& K. Lonka (Eds.), Writing as a learning tool: Integrating theory and practice (pp. 83-104). The Netherlands: Kluwer.

diSessa, A. A. (2004). Metarepresentation: Native competence and targets for instruction. Cognition and Instruction, 22(3), 293-331. doi:10.1207/s1532690xci2203_2

Fitzgerald, J., \& Shanahan, T. (2000). Reading and writing relations and their development. Educational Psychologist, 35(1), 39-50. doi:10.1207/S15326985EP3501_5

Galbraith, D., \& Torrance, M. (1999). Conceptual processes in writing: From problem-solving to text production. In D. Galbraith, \& M. Torrance (Eds.), Knowing what to write: Conceptual processes in text production. studies in writing (pp. 1-12). Amsterdam: Amsterdam University Press.

Gee, J. P. (2001). Reading as situated language: A sociokognitive perspective. Journal of Adolescent \& Adult Literacy, 44(8), 714-725.

Gee, J. P. (2004). Language in the science classroom: Academic social languages as the heart of school-based literacy. In W. Saul (Ed.), Crossing borders in literacy and science instruction: Perspectives in theory and practice (pp. 13-32). Newark, DE: International Reading Association/National Science Teachers Association.

Gunel, M., Hand, B., \& McDermott, M. A. (2009). Writing for different audiences: Effects on highschool students' conceptual understanding of biology. Learning and Instruction, 19(4), 354-367. doi:10.1016/j.learninstruc.2008.07.001

Hand, B. M., Gunel, M., \& Ulu, C. (2009). Sequencing embedded multimodal representations in a writing to learn approach to the teaching of electricity. Journal of Research in Science Teaching, 46(3), 225-247. doi:10.1002/tea.20282

Hand, B., Wallace, C. W., \& Yang, E. (2004). Using a science writing heuristic to enhance learning outcomes from laboratory activities in seventh-grade science: Quantitative and qualitative aspects. International Journal of Science Education, 26(2), 131-149. doi:10.1080/0950069032000070252

Hillocks, G. (1986). Resarch on written composition: New directions for teachimg. Urbana, IL: ERIC Clearinghouse on Reading and Communication Skills and National Conference on Research in English.

Holliday, W. G., Yore, L. D., \& Alvermann, D. E. (1994). The reading-science learning-writing connection: Breakthroughs, barriers, and promises. Journal of Research in Science Teaching, 31(9), 877-893. doi:10.1002/tea.3660310905

Kieft, M., Rijlaarsdam, G., \& van den Bergh, H. (2008). An aptitude-treatment interaction approach to writing-to-learn. Learning and Instruction, 18(4), 379-390. doi:10.1016/j.learninstruc.2007.07.004

Klein, P. (1999). Reopening inquiry into cognitive processes in writing-to-learn. Educational Psychology Review, 11(3), 203-270. Retrieved from http://dx.doi.org/10.1023/A:1021913217147

Lappalainen, H. (2011). Sen edestään löytää - äidinkielen ja kirjallisuuden oppimistulokset perusopetuksen päättövaiheessa 201O. ().Opetushallitus/Finnish National Board of Education. Retrieved from http://www.oph.fi/julkaisut/2011/sen_edestaan_loytaa 
Lavonen, J., \& Laaksonen, S. (2009). Context of teaching and learning school science in finland: Reflections on PISA 2006 results. Journal of Research in Science Teaching, 46(8), 922-944. doi:10.1002/tea.20339

Lemke, J. (1998). Multiplying meaning: Visual and verbal semiotics in scientific text. In J. R. Martin, \& R. Veel (Eds.), Reading science: Critical and functional perspectives on discourses of science (pp. 87-113). London: Routledge.

Newell, G. E. (2006). Writing to learn: How alternative theories of school writing account for student performance. In C. MacArthur, S. Graham \& J. Fitzgerald (Eds.), Handbook of writing research (pp. 235-247). Guilford, New York: The Guilford Press.

Nieswandt, M., \& Bellomo, K. (2009). Written extended-response questions as classroom assessment tools for meaningful understanding of evolutionary theory. Journal of Research in Science Teaching, 46(3), 333-356. doi:10.1002/tea.20271

Prain, V., \& Hand, B. (2005). Science and literacy. In K. Appleton (Ed.), Elementary science teacher education: Issues and practice (pp. 154-174). Mahwah, NJ: Association of Educators of Science Teachers Publication.

Prain, V. (2006). Learning from writing in secondary science: Some theoretical and practical implications. International Journal of Science Education, 28(2), 179-201. doi:10.1080/09500690500336643

Prain, V., \& Hand, B. (1996). Writing for learning in secondary science: Rethinking practices. Teaching and Teacher Education, 12(6), 609-626. doi:10.1016/So742-051X(96)00003-0

Räsänen, L. (1991). Tytöt ja fysikaalisten käsitteiden oppiminen. Kasvatus, 22(3), 185-194.

Rijlaarsdam, G., Couzijn, M., Janssen, T., Braaksma, M., \& Kieft, M. (2006). Writing experiment manuals in science education: The impact of writing, genre, and audience. International Journal of Science Education, 28(2-3), 203-233. doi:10.1080/09500690500336932

Rivard, L. O. P. (1994). A review of writing to learn in science: Implications for practice and research. Journal of Research in Science Teaching, 31(9), 969-983. doi:10.1002/tea.3660310910

Seufert, T. (2003). Supporting coherence formation in learning from multiple representations. Learning and Instruction, 13(2), 227-237. doi:10.1016/So959-4752(02)00022-1

Shanahan, T., \& Lomax, R. G. (1986). An analysis and comparison of theoretical models of the reading-writing relationship. Journal of Educational Psychology, 78, 116-123.

Shanahan, T., \& Lomax, R. G. (1988). Adevelopmental comparison of three theoretical models of the reading-writing relationship. Research in the Teaching of English, 22, 196-212.

Snyder, B. (1973). The hidden curriculum. California: Knopf.

Tarmo, M. (1991). Opettajan sukupuolilinssit. Kasvatus, 22(3), 195-204.

Välijärvi, J., Kupari, P., Linnakylä, P., Reinikainen, P., Sulkunen, S., Törnroos, J., . . . Arfmann, I. (2007). In Välijärvi J., Kupari P., Linnakylä P., Reinikainen P., Sulkunen S., Törnroos J. and Arfmann I. (Eds.), The finnish success in PISA - and some reasons behind it. Jyväskylä, Helsinki: Kirjapaino Oma OY.

Wallace, C. S., Hand, B. M., \& Prain, V. (2004). Writing and learning in the science classroom. Dordrecht, the Netherlands: Kluwer.

Yore, L., Bisanz, G. L., \& Hand, B. M. (2003). Examining the literacy component of science literacy: 25 years of language arts and science research. International Journal of Science Education, 25(6), 689-725. doi:10.1080/09500690305018 